\title{
GRAVITY STUDY OF THE AMPHIBOLITE SYNCLINE IN NAGU, SW-FINLAND
}

\author{
LENNART LAURÉN
}

LAurén, LenNart 1973: Gravity study of the amphibolite syncline in Nagu, SW-Finland. Bull. Geol. Soc. Finland 45, 53-60.

A gravity survey of the amphibolite syncline in Nagu, SW Finland was performed. The positive gravity anomaly obtained was interpreted by computing two-dimensional models for different cross-sections of the syncline. The possibility of gravitational disequilibrum as a contributing cause of the deformation of the syncline is discussed in the light of model experiments.

Lennart Laurén, Laboratory of Applied Geopbysics, University of Aarbus, Denmark.*)

\section{Introduction}

The Korpo-Nagu-Pargas area SW of the town of Turku, SW Finland, can structurally be characterized as a series of more or less closed syncline structures (Fig. 1). The synclines consist of amphibolite, diopside amphibolite and limestone, and the surrounding rock is mainly a migmatic granite (Edelman, 1960). The diopside amphibolites are generally considered to be of sedimentary origin (Metzger, 1945). According to Edelman (1960), volcanism played an important role in the formation of the main part of the amphibolites.

The subject of this study, the Nagu syncline, consists mainly of amphibolite rocks which are partly diopside-bearing. Limestone occurs sporadically as thin layers overlying the amphibolite. Concordant micaceous quartz-felspar-gneisses, which are often completely granitized, occur in-

\footnotetext{
* Present address: Paraisten Kalkki Oy-Pargas Kalk Ab, SF 21600 Pargas, Finland.
}

side the amphibolite syncline. The surrounding microcline granite is clearly conform with the basin structure and it often has a banded appearance with distinct, garnet-rich layers indicating sedimentary origin (Edelman, 1972).

From a geophysical point of view, the Nagu area, as a relatively simple complex of amphibolite and granitic rocks, offers a good opportunity for a gravity study. The high density contrast between the heavy amphibolite rocks and the light surrounding granites enables a fairly detailed gravity investigation of the syncline to be carried out.

The aim of the gravity study was to gather some information on the depth and shape of the amphibolite body. At the same time a satisfactory interpretation of the Nagu syncline would give some impulses to the tectonical interpretation of the neighbouring and more complex Pargas syncline (Fig. 1), previously described by Metzger (1945). 


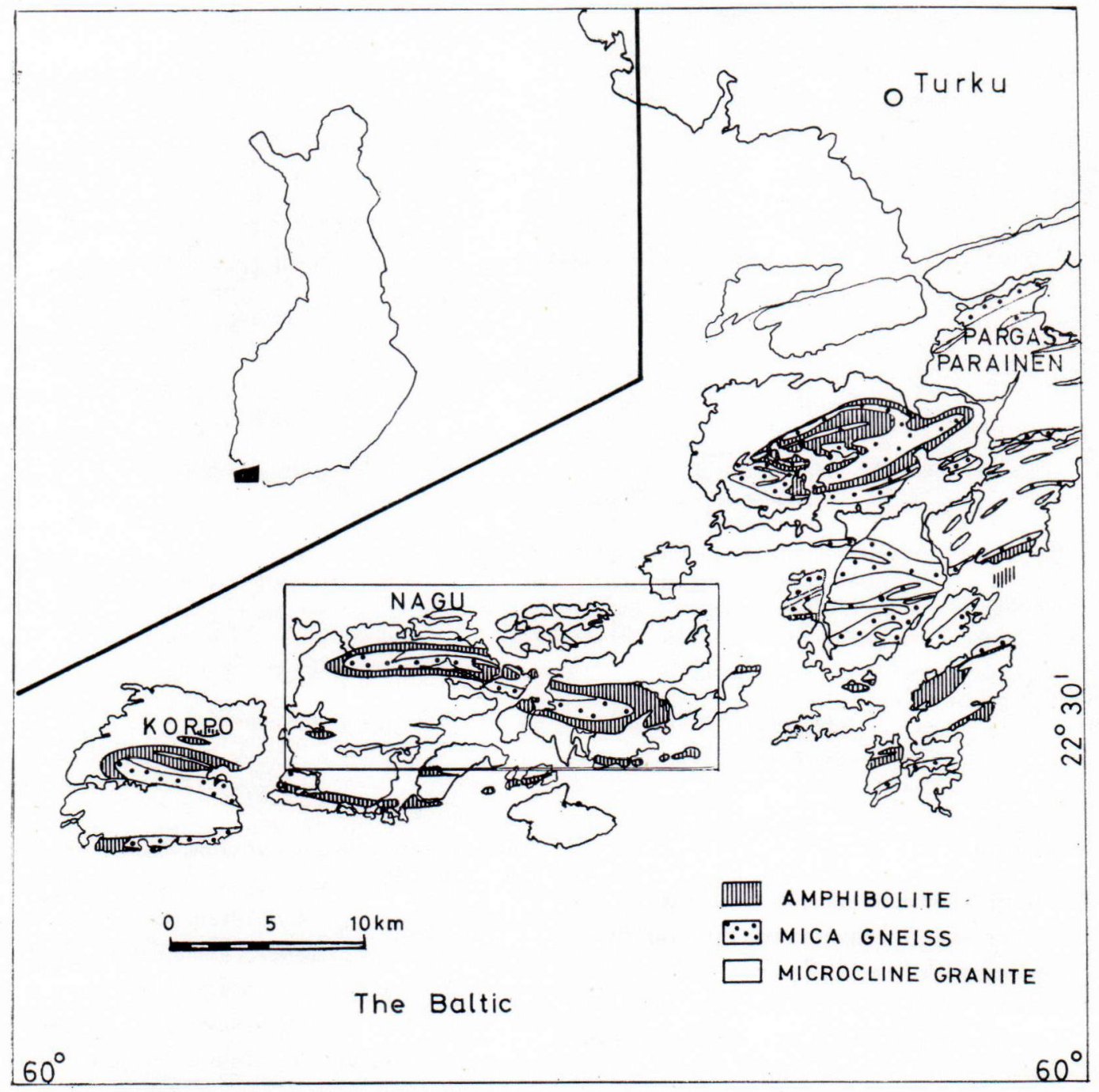

Fig. 1. Geology of the Korpo-Nagu-Pargas area. Simplified from Härme (1960)

\section{Gravity measurements}

The gravity measurements were performed with a Worden gravimeter. A total of 413 stations was measured. The archipelago in the area with its numerous islands, bays and sounds offers numerous measuring points directly at sea level. The altitude of the points not measured at sea level was mainly determined from the topographic map, that is, the measuring points were placed »directly on an altitude contour». According to an investigation at the Technical University of Helsinki the error in altitude for such points is in the order of $\pm 1 \mathrm{~m}$. A minor amount of points located in difficult terrain were levelled.

The resulting gravity map of Nagu shows a positive anomaly clearly associated with the amphibolitic rocks of the area (Fig. 2). The regional trend of the area was determined graphically 


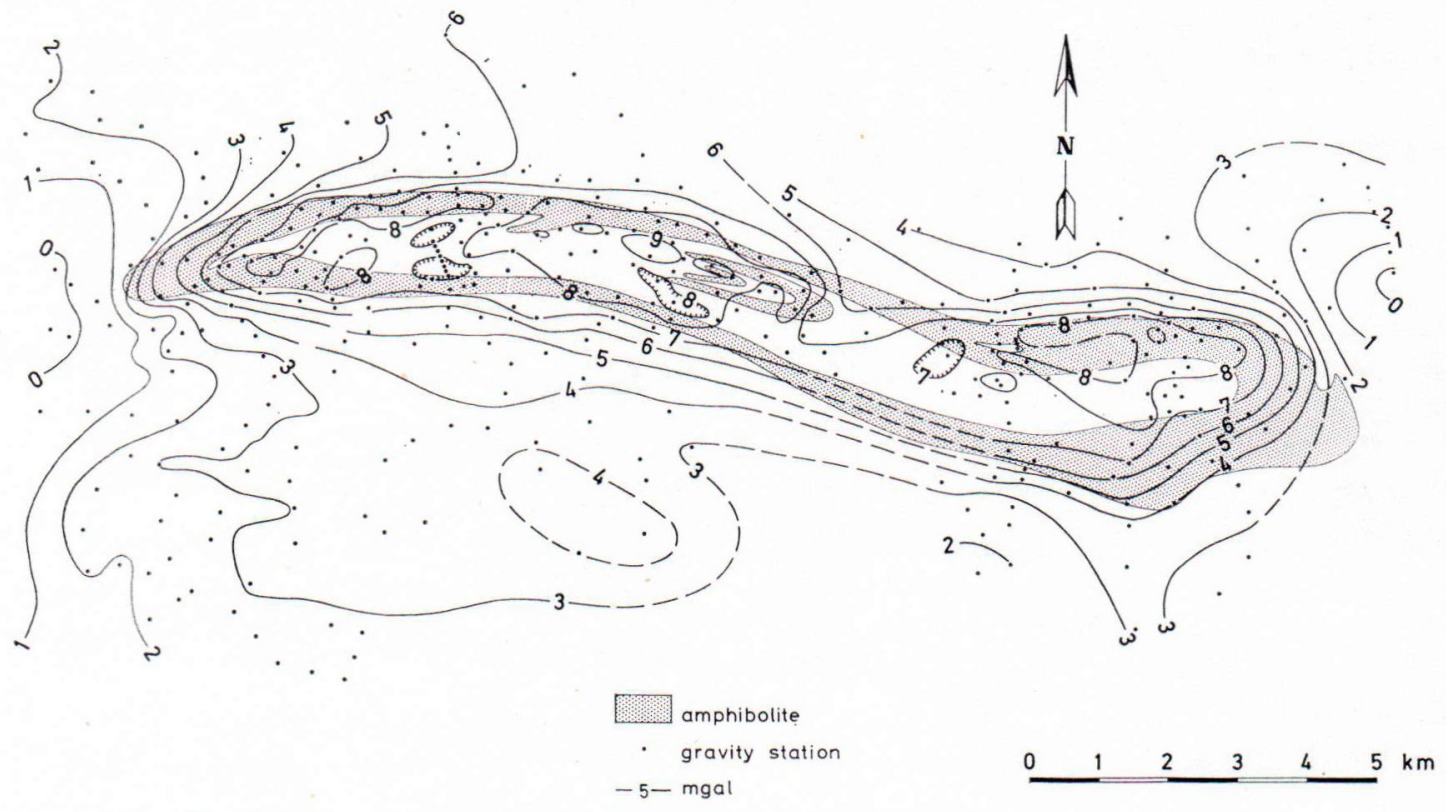

Fig. 2. Bouguer anomaly map of the Nagu area. Reduction density $=2.67 \mathrm{~g} / \mathrm{cm}^{3}$.

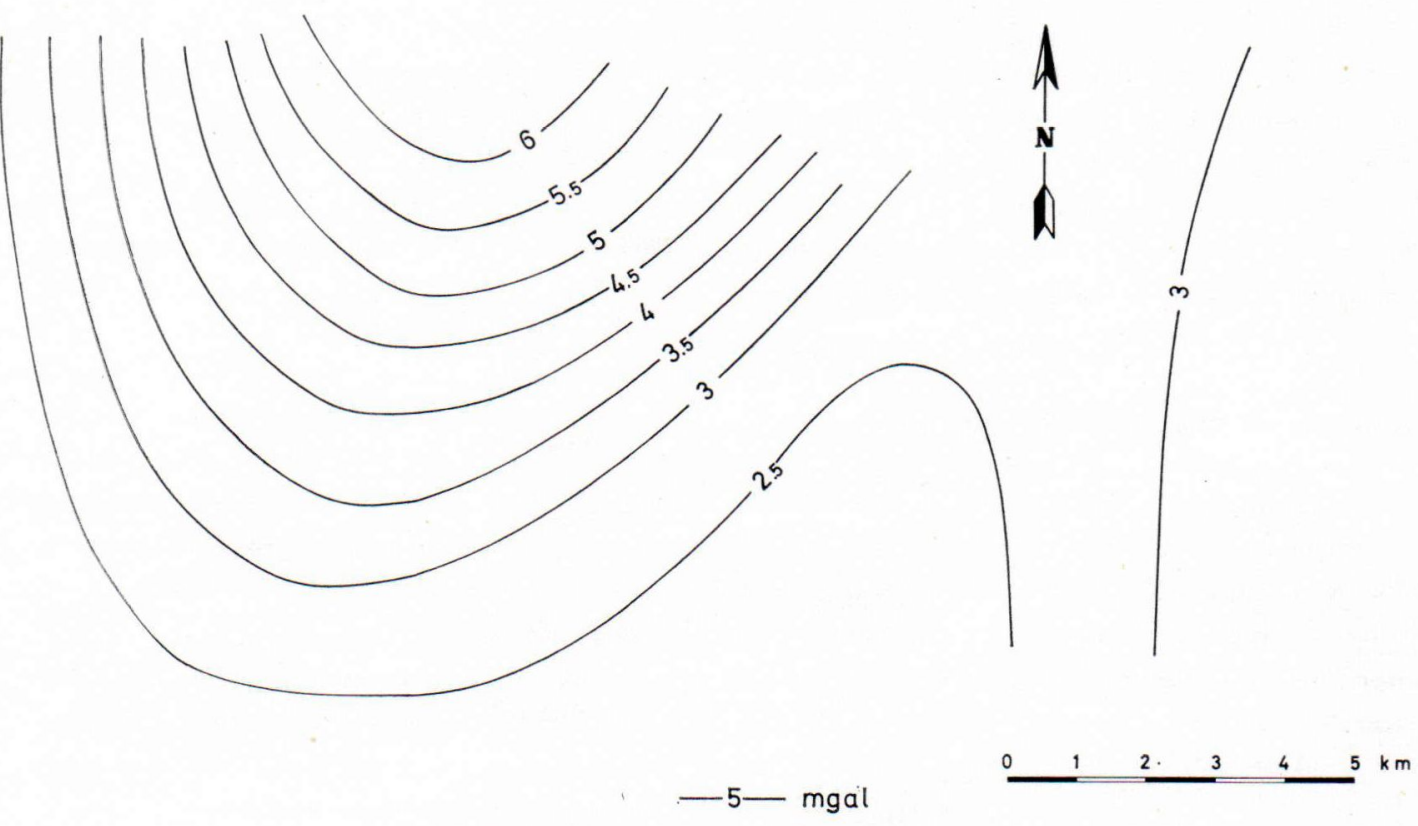

Fig. 3. Regional gravity of the Nagu area.

from $\mathrm{N}-\mathrm{S}$ running profiles. The regional field obtained (Fig. 3) forms a distinct high in the northern part of the area. Thus the measured gravity field in Nagu shows the combined effect of a local high associated with the superficial rocks and a regional high caused by deeper structures in the earth's crust. The resulting residual anomaly map further enhances the correlation between the amphibolitic rocks and the positive gravity anomaly (Fig. 4). 


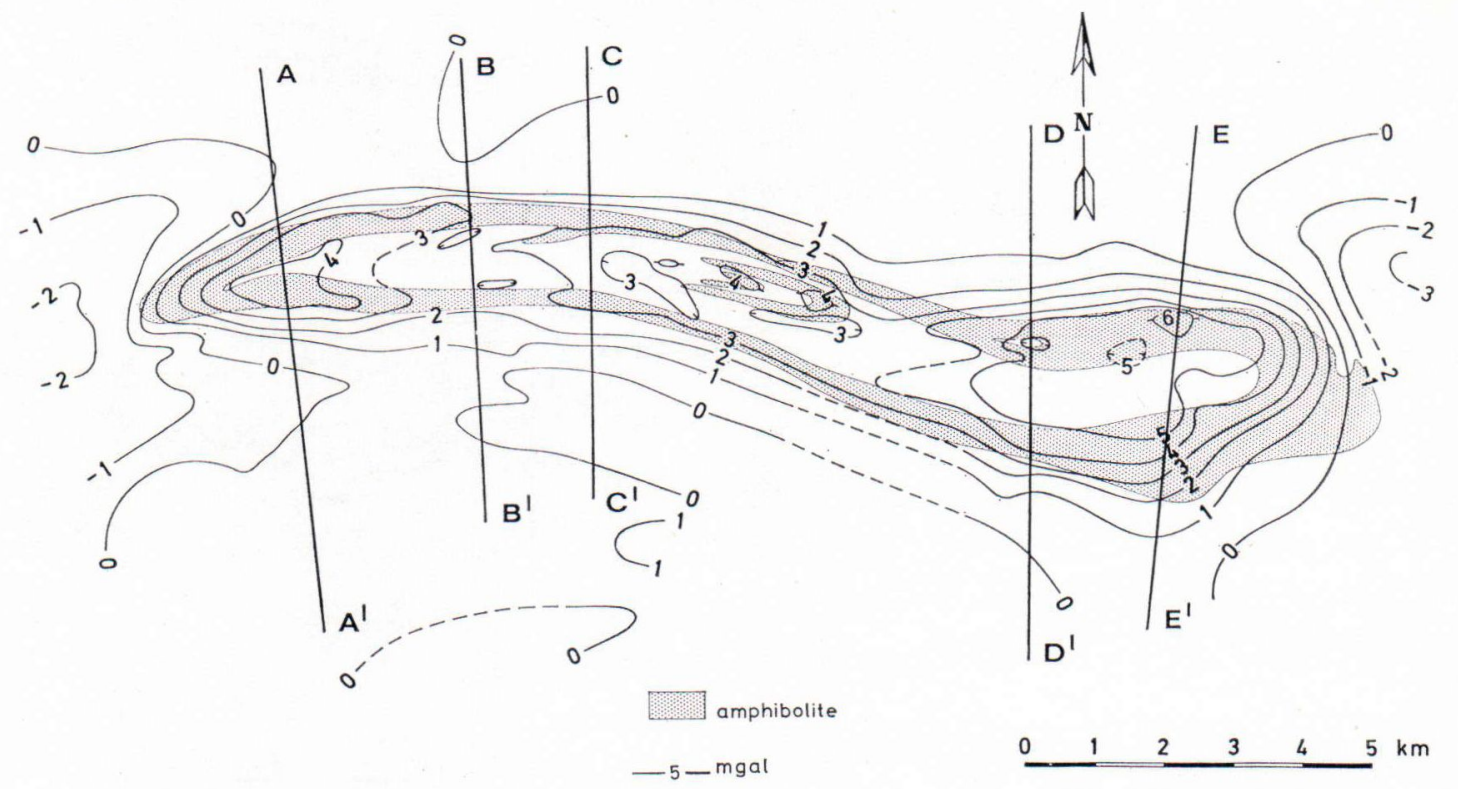

Fig. 4. Residual anomaly map of the Nagu area.

One conspicious feature of the residual map is the location of gravity highs with a magnitude of 4-5 mgals at both ends of the syncline. Another symmetrical feature is created by the two gravity lows outside the ends of the syncline and which apparently conform with the structure.

\section{Densities of the rocks in the area}

The sampling for the density determinations covers the area fairly well, except for the easternmost part (Lillandet), where only a limited number of samples (17) was taken. The density was determined by weighing the sample in air and water.

\begin{tabular}{ccccc}
\multicolumn{1}{c}{ Rock } & n & $\begin{array}{c}\text { Mean } \\
\text { density }\end{array}$ & $\begin{array}{c}\text { Standard } \\
\text { deviation }\end{array}$ & $\begin{array}{c}\text { Density } \\
\text { range }\end{array}$ \\
Amphibolite .. & 80 & 2.93 & 0.04 & $2.80-3.12$ \\
Granite $\ldots \ldots$. & 35 & 2.63 & 0.02 & $2.59-2.66$ \\
Gneiss $\ldots \ldots$ & 18 & 2.675 & 0.02 & $2.65-2.72$
\end{tabular}

The few density values from the eastern part of the area do not indicate any significantly different density there and it seems reasonable to assume a homogenous density distribution for each lithological unit of the area.

\section{Interpretation of the gravity measurements}

The interpretation was performed as model computations for a number of profiles across the syncline (Fig. 4) utilizing end-corrected twodimensional models with a polygonal crosssection. The computations were performed by a GIER computer using a program by $H$. Henkel at the Laboratory of Applied Geophysics, Aarhus University.

It is evident that an interpretational problem of this type cannot be uniquely solved by one set of computed models with a satisfactory fit. However, the geological and petrophysical data established for the area considerably limit the number of possible models. All geological observations indicate that the northern and southern amphibolite are parts of the same layer folded into a syncline. The contacts between the amphibolite and the surrounding rocks are fairly well established. In model terms this means 
models consisting of one continuous layer with fixed surface-reaching parts which sharply restricts the variance in shape of possible models. The density contrast can also be determined with sufficient certainty, since the density distribution in the different rocks is fairly homogenous and consequently the depth range of the possible models is limited.

The resulting models are shown in Figures 5 and 6 .
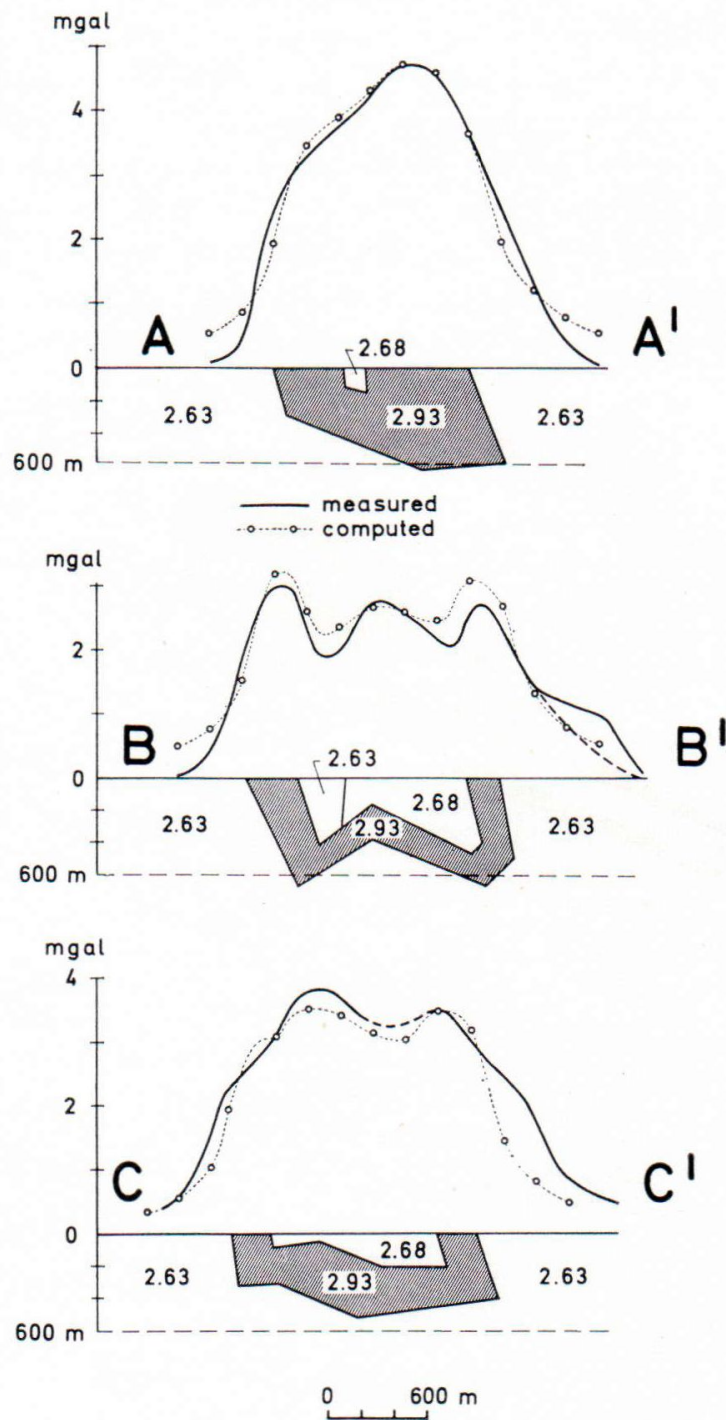

Fig. 5. Two-dimensional models from the western part of the Nagu area.
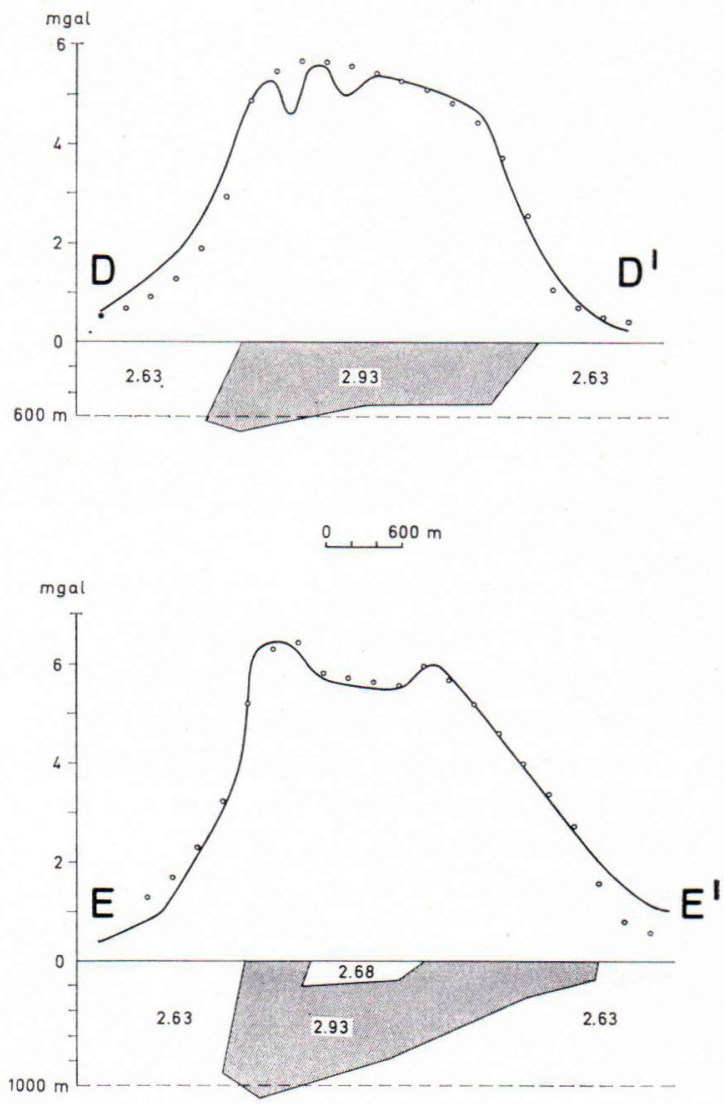

Fig. 6. Two-dimensional models from the eastern part of the Nagu syncline.

A systematic change in the attitude and depth of the models can be seen in the area eastwards from the western end of the syncline. The westernmost model (Profile A-A') clearly dips south at a depth of c. $600 \mathrm{~m}$. The gravity anomaly consists of one single maximum, indicating that the low-density gneisses inside the syncline are thin compared with the amphibolite.

The second profile (B-B') has three distinct gravity maxima, the two outermost peaks corresponding to the amphibolite limbs. Characteristic of the model is the upwarping of the bottom of the syncline in compensation for the middle peak. Comparing profiles $\mathrm{A}-\mathrm{A}^{\prime}$ and $\mathrm{B}-\mathrm{B}^{\prime}$ it is obvious that the folding has caused a compaction of the end of the syncline. 
The next profile, $\left(\mathrm{C}-\mathrm{C}^{\prime}\right)$, is clearly dominated by the middle peak. The southern amphibolite limb can still be seen as a distinct maximum, but the northern limb is merely indicated by a knick on the northern flank of the middle peak. In the corresponding model the upwarping of the bottom has come quite near to the surface and is combined with a thickening of the amphibolite. A southward tilt is still indicated.

Eastwards from profile $\mathrm{C}-\mathrm{C}^{\prime}$, in the central part of the syncline, the amphibolite is outcropping. The central outcrop combined with the indicated upwarping of the bottom of the syncline indicates that this outcrop represents the bottom of the syncline. Eastward from this proposed axial culmination the "gravity picture» of the amphibolite syncline changes fairly sharply. First, the anomaly values are considerably greater than in the western part, which is partly due to the greater width of the amphibolite. Secondly, the low-density rocks inside the syncline have little effect on the gravity profiles. Especially in profile D-D' the rocks inside the syncline must be very limited in depth. For the sake of simplicity they have been neglected in the model computations for this profile. The models also clearly dip northwards, contrary to the southward dip of the western part of the syncline. The model computed for the easternmost profile (E-E') is rather assymmetrical, with a steeply dipping northern limb and a gently dipping southern limb. This model also attains the greatest depth value of the syncline, the depth of the steep part being c. $1000 \mathrm{~m}$.

The upwarping of the bottom in the central part of the syncline, as indicated by the quantitative interpretation, is also in good agreement with the conclusions of a qualitative valuation

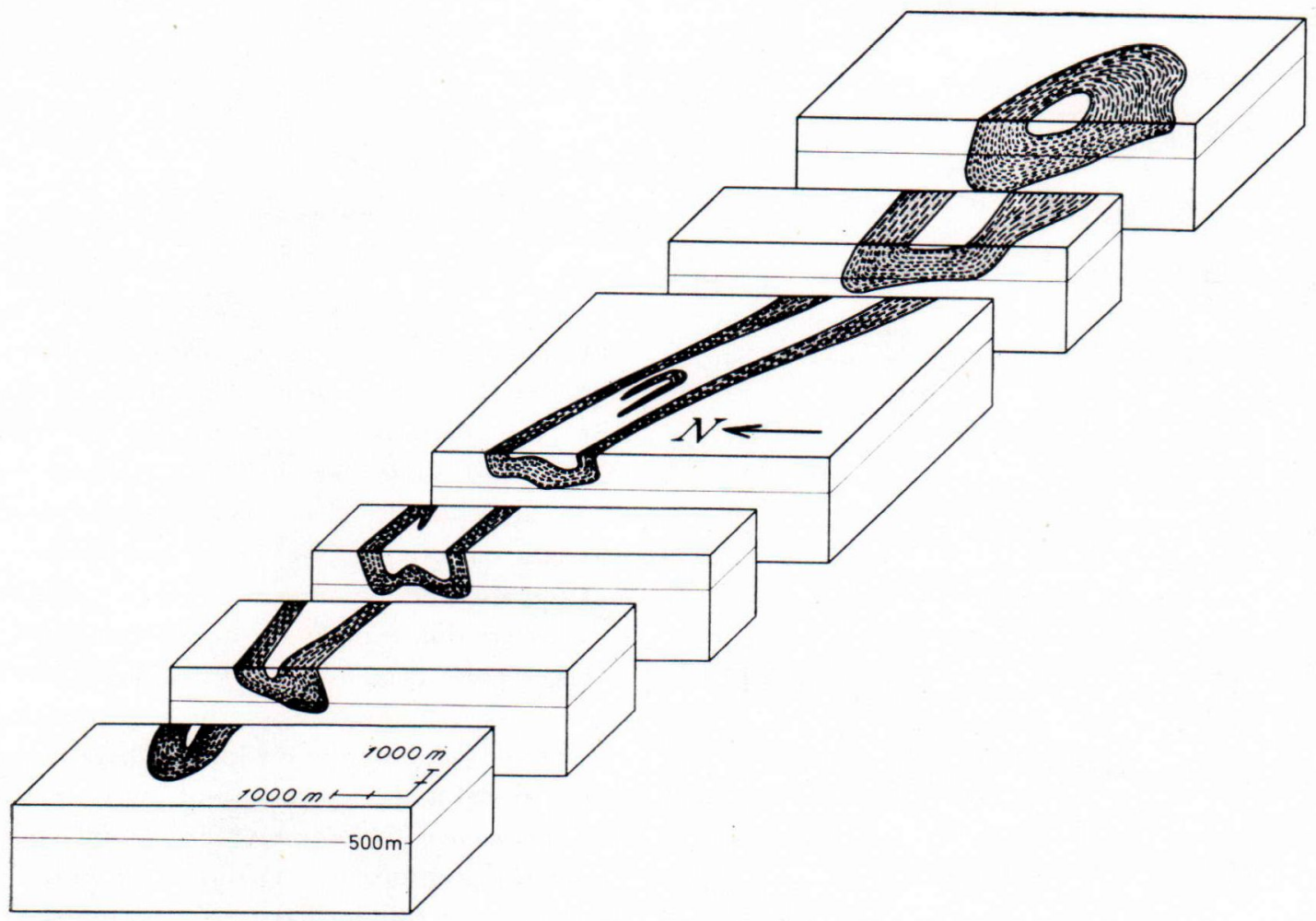

Fig. 7. Isometric projection of the Nagu syncline based on the gravity models. 
of the residual anomaly map: The alternative interpretation would be that the central outcrop represents a second overlying amphibolite layer. Two amphibolite layers imply a larger anomalous mass and consequently the greatest gravity anomalies should be recorded in the central part of the syncline. As the residual anomaly map in fact shows more or less the opposite, the twolayer explanation is incompatible with the gravity measurements.

The results from the interpretational profiles are compiled to a three-dimensional model in Fig. 7. Apart from showing the culmination, the model also shows the twisting of the syncline around the culminating part: the western part dips south and the eastern part dips north.

\section{Mass estimate of the amphibolitic rocks}

The anomalous mass causing the gravity anomaly was calculated by determining from the anomaly map the integral $\int \Delta \mathrm{gdS}$, where dS denotes the areal element. This calculation does not involve any density values. By introducing the actual density values of the area, approximate values for the mass and volume of the amphibolitic rocks can be computed.

Results for the Nagu amphibolite:

Anomalous mass: ......... 3.4 $40^{9}$ ton Mass of the amphibolitic rocks:.. $33 \cdot 10^{9}$ ton Volume of the amphibolitic rocks: $11.2 \mathrm{~km}^{3}$

The values obtained probably represent a minimum estimate. One could ponder about the possibility of the amphibolite having once formed a horizontal layer of uniform thickness. If it is assumed that the thickness of such a layer is equal to that of the thinner parts of the present syncline (c. $250 \mathrm{~m}$ ), the corresponding areal extent would be c. $45 \mathrm{~km}^{2}$ compared with the present value of $30 \mathrm{~km}^{2}$.

\section{Discussion}

According to the gravity interpretation the characteristic feature of the amphibolite syncline is the compaction i.e. concentration of highdensity material at both ends of the syncline, combined with the culmination of the central part. In connection with this there are some interesting physical aspects that should be discussed.

It is reasonable to assume that the amphibolite originally formed a more or less horizontal layer, which was either sedimentary, volcanic or intrusive. This means a heavy, basic layer resting on an acid, low-density basement. In order to attain gravitational equilibrum the heavy amphibolite layer would have tended to subside into the granite, and this sinking movement would have caused a deformation of the layer.

The experiments of Ramberg (1967) on the behaviour of subsiding heavy bodies revealed a marked tendency for subsiding, originally horizontal layers to form anticlinal structures due to the faster sinking of the edges.

It must be emphasized that the proposed subsidence can only be a contributing factor to the tectonic deformation of the Nagu structure. It is certain that the essential force in the shaping of the Nagu syncline were the same orogenic movements that affected most supracrustal rocks of SW Finland. On the other hand, it is interesting to compare the culmination of the Nagu syncline with the anticlinical bending of the subsidence models of Ramberg. There are two possible ways in which the culmination could have been formed: updoming of the central part or sinking of the outer parts. Of the two, the sinking alternative seems the more compatible with the indicated thickening of the ends of the syncline.

One could also speculate on the possible connection between a subsidence and the gravity lows bending conformly around the ends of the syncline. The experiments by Ramberg (1967) showed that sinking movements cause a flow 
of substratum material around the subsiding edges of a body. The gravity lows could represent a backwash pattern created by such a flow.

Metzger (1945) stressed the possible role of gravitational sinking in the shaping of the neighbouring amphibolite syncline in Pargas.

After demonstrating that a gravitational sinking possibly contributed to the deformation of the Nagu syncline, the next step would be to try to fit the subsidence movement into the tectonic pattern of the syncline. Without entering upon any detailed tectonic analysis it is apparent that the subsidence is without significance until the final stages of the orogeny and after it. On the other hand, the indicated compaction of the sinking parts postulates a certain plasticity of the amphibolite material, which sets a lower limit temperature for the event. It should also be possible provided one can make reasonable assumptions about the viscosity of the rocks involved, to calculate the time required for a subsiding syncline to develop into the structure outlined by the gravity model.

Acknowledgements - Financial aid from the Outokumpu Foundation facilitated the practical performance of the measurements, for which thanks are due.

I also wish to thank Professor Nils Edelman, Geological-Mineralogical Institute, Åbo Academy and my colleagues at the Institute of Applied Geophysics for valuable discussion during the work. I am also indebted to Mr. Erik Jensen for assistance in the field measurements, Mrs. Hilde Christensen for making the density determinations and to Mrs. Inge Skou and Mrs. Toini Tomminen for drawing the pictures. Mrs. Gillian Häkli kindly corrected the English of the manuscript.

\section{REFERENCES}

Edelman, Nils (1960) The Gullkrona region. Bull. Comm. géol. Finlande 187.

Edelman, Nils (1972) A porphyroblastic Granite with Preserved Bedding. Geol. För. Stockholm För., Vol. 94, No. 549.

Härme, M. (1960) Suomen geologinen yleiskartta - The general geological map of Finland. Lehti - Sheet B1.
Metzger, Adolf A. T. (1945) Zur Geologie der Inseln Alö und Kyrklandet in Pargas - Parainen, S. W. Finnland. Acta - Acad. Aboens., Math. Phys. XV, 3.

Ramberg, H. (1967) Gravity, deformation and the earth's crust. Academic Press, London.

Manuscript received, June 1, 1972. 